FERREIRA, M.; MARTINS, E.; GONÇALVES, K. O estágio supervisionado como espaço de reflexão sobre o exercício da docência em química no ensino médio

ARTIGOS

\title{
O estágio supervisionado como espaço de reflexão sobre o exercício da docência em química no ensino médio
}

Maira Ferreira Eliezer Martins Kauana Gonçalves

RESUMO: O estágio supervisionado é componente curricular obrigatório em cursos de Licenciatura. Essencial para a formação de professores, o estágio envolve atividades de prática profissional em situações reais de trabalho, possibilitando tempos e espaços de aprendizagem da prática docente e permitindo ao estudante analisar seu ambiente profissional. Esta etapa da formação docente pode ser entendida como um período de interstício entre as aprendizagens construídas na academia e os saberes produzidos na prática profissional, uma vez que, durante os estágios, os licenciandos são perpassados pelas teorizações e práticas da universidade e da escola. Esse tempo de aprendizagem contempla uma proposta de formação acadêmica que considera os saberes professorais e as experiências relacionadas à prática do cotidiano na relação com o âmbito escolar, o local que exercerão sua futura profissão (TARDIF, 2002, apud SILVA, 2009). Fazer essa transição da cultura acadêmica para a cultura escolar tem sido um dos grandes desafios em cursos de formação de professores.

PALAVRAS CHAVE: Ensino de Química; Formação de Professores; Estágio Supervisionado.

\section{The stage supervised as a space for reflection on the exercise of teaching in chemistry in the high scool}

\begin{abstract}
The supervised internship is compulsory curricular component in undergraduate courses of the teacher training. Essential for teacher training, the internship involves activities of professional practice in real working situations, allowing time and spaces of learning of the teaching practice and allowing the student to analyze their professional environment. This stage of teacher training can be understood as a period of intersection between the learning acquired in the academy and the knowledge produced in professional practice, since during the internships, the graduates are permeated by the theories and practices of the university and the school. This time of learning contemplates a proposal of academic formation that considers the professorial knowledge and the experiences related to the daily practice in the relation with the school scope, the place that will exert its future profession (TARDIF, 2002, apud SILVA, 2009). transition from academic culture to school culture has been a major challenge in teacher training courses.
\end{abstract}

KEYWORDS: Chemistry teaching; Teacher training; Supervised internship 


\section{INTRODUÇÃO}

O estágio supervisionado é componente curricular obrigatório em cursos de Licenciatura. Essencial para a formação de professores, o estágio envolve atividades de prática profissional em situações reais de trabalho, possibilitando tempos e espaços de aprendizagem da prática docente e permitindo ao estudante analisar seu ambiente profissional. Esta etapa da formação docente pode ser entendida como um período de interstício entre as aprendizagens construídas na academia e os saberes produzidos na prática profissional, uma vez que, durante os estágios, os licenciandos são perpassados pelas teorizações e práticas da universidade e da escola. Esse tempo de aprendizagem contempla uma proposta de formação acadêmica que considera os saberes professorais e as experiências relacionadas à prática do cotidiano na relação com o âmbito escolar, o local que exercerão sua futura profissão (TARDIF, 2002, apud SILVA, 2009).

Fazer essa transição da cultura acadêmica para a cultura escolar tem sido um dos grandes desafios em cursos de formação de professores. Para Fávero (2011, p.58), a "universidade tem uma realidade histórica, e sociocultural, que contempla diferentes visões do mundo, uma dessas é desenvolvida pelos futuros professores durante seu curso de formação, com relação à escola e à docência". Ainda, com base na concepção da autora, a universidade pública necessita estar atenta, ter competência suficiente e dedicação redobrada para formar os futuros profissionais que a frequentam e que, muitas vezes, têm dificuldades em articular conhecimentos teóricos aprendidos na universidade com os conhecimentos reconhecidos no ambiente da prática profissional (FÁVERO, 2011).

Isso é referido por licenciandos, inclusive os que já tenham participado de ações de iniciação à docência em seus cursos de formação ou em projetos e programas financiados/incentivados por políticas públicas educacionais, pois, dizem que, ao chegar à escola para a realização dos estágios, parecem estar vivenciando, pela primeira vez, a profissão docente, em um espaço institucional com finalidades e práticas diferentes das realizadas na universidade.

A preocupação com o exercício da profissão docente implica entender, entre outros aspectos, como se dá o funcionamento da escola, não mais observando ou colaborando em aulas, mas como professor/a responsável por uma turma de alunos. Essa vivência profissional durante o curso de licenciatura pode se tornar mais difícil em meio aos frequentes anúncios e implantações de reformas curriculares.

No caso da rede pública estadual do Rio Grande do Sul, uma reforma anunciada como Ensino Médio Politécnico' (EMP) (2012-2014), teve como proposta a reestruturação da matriz curricular e metodológica no ensino médio, sendo os indicativos de mudança, a organização do currículo por áreas de conhecimento e a dimensão interdisciplinar a ser realizada na componente curricular Seminários Integrados (SEDUC/RS, 2011). Na época, a proposta foi apresentada como sendo uma possível solução para a melhoria do sistema educacional, em função dos índices preocupantes de baixo rendimento na educação, conforme o censo escolar de 2010 (SEDUC/RS, 2011).

Como ocorre em processos de reformas, a implantação do EMP (SEDUC//RS, 2012) gerou discussões na escola e, também, em cursos de licenciatura, que precisaram preparar os licenciandos/estagiários para a vivência de práticas disciplinares e interdisciplinares, considerando os princípios da reforma implantada sem

1 O Ensino Médio Politécnico no Rio Grande do Sul (2012-2014) foi implantado como uma proposta de reestruturação do currículo no Ensino Médio do Estado, tendo em sua concepção a articulação das áreas de conhecimento e suas tecnologias, relacionada a eixos que englobam: cultura; ciência; tecnologia e trabalho, promovendo a relação do sujeito com vida em cidadania (SEDUC/RS, 2011). 
discussão com quem implementa as reformas: os professores. Não se trata de desconsiderar a pertinência da proposta, que tinha entre seus princípios a educação pela pesquisa e a abordagem menos fragmentada dos conhecimentos, mas chamar a atenção para a necessidade de preparar os profissionais da educação que colocariam a proposta em funcionamento.

A pesquisa, realizada com licenciandos/estagiários de um curso de licenciatura em Química em uma universidade do sul do estado do Rio Grande do Sul, considerou a pertinência de investigar a experiência dos estagiários na escola, considerando-a como espaço para a formação e reconhecimento da profissão docente.

É importante destacar que, mesmo conhecendo a escola e seu funcionamento, participando de discussões ou sendo incentivados para a realização de práticas inovadoras, contextualizadas e com dimensão interdisciplinar, desde o início do curso de licenciatura, os licenciandos referem que quando entram na escola para os estágios sentem insegurança, pois veem-se ocupando o lugar de professores, realizando práticas institucionais e sendo responsáveis por uma turma de alunos.

Este artigo trata, então, sobre os estágios supervisionados em Química no Ensino Médio, visando compreender como os licenciandos vivenciam esse período de formação, na universidade e na escola, no desenvolvimento de suas práticas na escola, considerando as orientações e perspectivas teóricas abordadas no curso de licenciatura para o ensino de Química.

\section{CAMINHOS DA PESQUISA}

O estudo procurou analisar como os licenciandos/estagiários colocam em operação as orientações legais e pedagógicas que recebem, tanto na universidade quanto na escola, considerando as demandas da educação escolar, de modo a conhecer suas percepções sobre o período de estágio e os efeitos dessa etapa nas perspectivas de exercício da profissão docente.

Como uma das primeiras ações da pesquisa, analisamos documentos oficiais (Lei de Diretrizes e Bases da Educação, Resoluções contendo Diretrizes Curriculares sobre a Formação de Professores e sobre a reforma do Ensino Médio Politécnico/RS), visando conhecer os princípios legais para a organização curricular em cursos de Licenciatura e no Ensino Médio no estado do Rio Grande do Sul. Tal análise se mostrou uma "técnica valiosa de abordagem de dados qualitativos, complementando as informações obtidas" (LÜDKE, ANDRÉ, 1986, p.38), com os licenciandos.

Concomitante ao estudo e análise de documentos, os estagiários do curso de licenciatura pesquisado foram convidados a responder um questionário ao final de cada estágio supervisionado, em um estudo exploratório, que versou sobre: a recepção dos estagiários pela coordenação da escola e pelos professores titulares; a facilidades/dificuldade em ter acesso aos documentos da escola; o acompanhamento do/a professor/a titular da escola (realização de reuniões ou encontros regulares para planejamento de metodologias para o ensino); a receptividade e relação com os alunos no exercício da docência; a infraestrutura da escola para a realização das atividades ( uso de laboratório de Ciências, de biblioteca, de laboratório de informática, etc.); o modo como o/a estagiário/a se sentiu na(s) escola(s) e na(s) turma(s) ao longo de cada estágio (bem-estar/ mal-estar); a perspectiva da carreira docente (o estágio como fator motivador/desmotivador); e sugestões para melhorar a experiência de estágio, considerando a perspectiva dos acadêmicos com relação ao exercício da profissão docente. 
O estudo exploratório possibilitou a organização de um roteiro de entrevista semiestruturada com os estagiários, considerando-a "um roteiro com perguntas principais, complementadas por outras questões inerentes às circunstâncias momentâneas à entrevista" (MANZINI, 2004, p.2). O roteiro foi produzido com a intenção de aprofundar algumas questões e conhecer com maior detalhamento as experiências vivenciadas pelos licenciandos ao longo dos estágios. Para tal, organizou-se uma roda de conversa com 10 estagiários (identificados de L1 à L10), após terem cursado as três disciplinas de Estágio Supervisionado.

A entrevista em roda de conversa foi gravada e transcrita, compondo dados para análise da pesquisa. As respostas dos estagiários, apontadas pelo roteiro da entrevista, tratam sobre sua percepção acerca de: reação dos estudantes do ensino médio com a chegada do estagiário (visto como atrapalhando/auxiliando para a sua aprendizagem); adequação/não adequação de tempos para: observação de aulas, docência compartiIhada e regência de classe nos diferentes estágios; a experiência em ter (não ter) de acompanhamento dos professores titulares e/ou dos professores na universidade); a vivência (ou não) em ações interdisciplinares (áreas/disciplinas, tempo/espaço); ao interesse da direção, supervisores/coordenadores e professores da escola em participar da formação inicial de professores; a satisfação/insatisfação do exercício da docência compartilhada e da regência de classe, (em relação a perspectiva de seguir a profissão docente.

Os dados da pesquisa foram registrados e analisados seguindo a metodologia de Análise de Conteúdo (BARDIN, 2011). O trabalho analítico de extração de unidades de significado, considerou as manifestações dos estagiários na roda de conversa, bem como, as informações sobre as reformas curriculares e sobre os estágios supervisionados nos documentos oficiais, para possibilitar um processo de categorização, tomado como "uma operação de classificação de elementos constitutivos de um conjunto por diferenciação seguida de um reagrupamento" (FRANCO, 2008, p. 59).

As questões que orientaram o roteiro da entrevista constituíram categorias (a priori), com elementos "pré-determinados em função da busca a uma reposta especifica do investigador" (FRANCO, 2008, p.60), mas além dessas, outras questões emergiram durante o registro dos dados como, por exemplo, o incômodo dos estagiários de serem comparados com o professor titular ou a discussão sobre a falta de preparo para lidar com a inclusão escolar.

Assim, foram elencadas as seguintes categorias de análise: a) a relação dos alunos da escola com os estagiários e comparação desses com o/a professor/a titular; b) adequação dos tempos para estágio de observação, de docência compartilhada e de docência/regência; c) acolhimento e acompanhamento do/a professor/a da escola; d) inclusão e docência; e) metodologias para o ensino e interdisciplinaridade; f) avaliação da experiência e da escola como campo de estágio; g) motivações e expectativas para o estágio e a profissão docente. Considerando os espaços institucionais inerentes ao contexto de formação de professores para a Educação Básica, essas categorias iniciais possibilitaram reflexões que apontam o estágio supervisionado como espaço que precisa propor maior diálogo entre universidade e escola, uma vez que compõe um cenário de expectativas, experiências e perspectivas para futuros professores.

\section{ESTÁGIO SUPERVISIONADO COMO ESPAÇO DE DIÁLOGO ENTRE UNIVERSIDADE E ESCOLA}

O estágio supervisionado, parte do processo de formação inicial de professores, oportuniza avaliar novas formas de pensar os conteúdos, a formação docente, a escola e seus currículos, o que implica pensar o estágio de forma diferente (PIMENTA, 2012). 
Uma retrospectiva histórica em cursos de licenciatura mostra que a configuração dos estágios foi mudando ao longo do tempo. Inicialmente, no Brasil, nos anos de 1930, com a expansão de censos superiores de licenciatura foram instituídas leis estaduais que regulamentavam os estágios. Na década seguinte, anos de 1940, houve a implementação da Lei Orgânica do Ensino Normal (Decreto - Lei nº 8.530 de 02 de janeiro de 1946) e com ela a formação de professores para a escola primária, com estágios como parte dessa formação. A partir da segunda metade do séc. XX, nos anos de 1970, com a LDB n 5.692/71 e, nos anos de 1980, com o Movimento dos Educadores, mudanças mais significativas aconteceram na concepção dos estágios, havendo a preocupação com as especificidades de orientação dessa prática, em função dos diferentes perfis de professores oriundos de diferentes áreas e diferentes cursos de licenciatura. (PIMENTA, 2012, p. 28 - 34).

Mesmo com os movimentos em prol de mudanças nos cursos de formação de professores, foi desde o início dos anos de 2000, com as Resoluções 01 e 02 (BRASIL, 2002a, 2002b), reafirmada recentemente com a Resolução 02/2015 (BRASIL, 2015), que o papel dos estágios em cursos de formação de professores foi redimensionado, com aumento de maior carga horária ao estágio curricular obrigatório e maior articulação com as escolas de educação básica. O aumento substancial da carga horária de estágio indica a obrigatoriedade de imersão do licenciando na prática profissional, mas cria, por outro lado, uma desenfreada busca dos estudantes por um espaço nas escolas para a realização de estágio, o que, especialmente em cidades com poucas escolas de ensino médio, pode tornar difícil, desgastante e frustrante a entrada para estágio nas instituições de ensino.

Estudos realizados no campo da formação de professores e dos estágios supervisionados geram produção científica acerca das políticas públicas para a formação de professores, da estrutura curricular dos cursos de licenciatura e dos estágios como espaço de formação e da organização de tempos e espaços para estágio curricular (PEREIRA, 1999; NÖRNBERG, 2017), ou sobre a realidade das escolas e da construção de conhecimento pelos professores na experiência com a docência (MALACARNE, 2007), ou, ainda, sobre as dificuldades enfrentadas pelos licenciandos ao longo do processo formativo para a produção de saberes docentes no decorrer da experiência com a docência na educação básica (MELO, 2007), entre outros estudos.

No caso da pesquisa de Melo (2007), seu estudo se aproxima do estudo que realizamos, uma vez que, também, foi realizado com alunos de um curso de licenciatura em Química de uma universidade pública federal, sendo alguns resultados semelhantes aos que encontramos, mesmo se tratando de uma universidade em outra região do Brasil. A produtividade envolvendo estudos sobre a formação de professores em cursos de licenciatura e sobre as práticas realizadas na educação básica vem acompanhada de recorrentes anúncios de mudanças por meio de reformas curriculares como a já referida reforma, no estado do Rio Grande do Sul, do Ensino Médio Politécnico (SEDUC/RS, 2011) ou, em nível federal, pelas Diretrizes Curriculares Nacionais para o Ensino Médio (BRASIL, 2012).

Normalmente, proposições de mudanças na escola apontam a interdisciplinaridade como princípio de reestruturação curricular, tal como destacam as pesquisas que indicam a centralidade da interdisciplinaridade em reformas curriculares e nas dimensões pedagógicas da ação docente no âmbito escolar (BOVO, 2004), ou tratam sobre aspectos históricos envolvendo o "surgimento" da interdisciplinaridade em meio aos currículos marcados pela disciplinarização (VEIGA-NETO, 1996).

Investigações sobre a concepção dos professores com relação à interdisciplinaridade e ao desenvolvimento de ações interdisciplinares (AUGUSTO et al, 2004), ou sobre o perfil de professores que desenvolvem práticas interdisciplinares na educação básica (GARCIA, 2009), mostram a necessidade de reflexão junto aos estagiários sobre o que vem 
sendo anunciado como indicativo de mudança na educação escolar e a avaliação do que têm sido compreendido como ação interdisciplinar, tanto na universidade, quanto em escolas, locais de estágios de docência.

Segundo o Art. $5^{\circ}$ das Diretrizes Curriculares Nacionais para o Ensino Médio é necessário que haja "a integração de conhecimentos gerais e técnico-profissionais na perspectiva da interdisciplinaridade e da contextualização" (BRASIL, 2012, p.2), sendo orientado aos professores que tratem, na escola, conhecimentos relevantes para o cotidiano dos alunos em uma organização curricular que privilegie áreas de conhecimento e não mais disciplinas isoladas.

Nesse sentido, a interdisciplinaridade surgiria como necessidade, como princípio organizador do currículo e como método de ensino e aprendizagem, considerando que os conceitos de diversas disciplinas estariam relacionados para a compreensão dos objetos de estudo. (BRASIL, 2007, p. 52).

Mas, propor práticas interdisciplinares não é tarefa simples, se levarmos em consideração as diferentes concepções imbricadas neste conceito, fazendo com que, por vezes, seja tomada como junção de componentes curriculares. Para Rosa (2010, p. 410), "nas universidades, a formação disciplinar tem sido quase única e exclusiva, fazendo com que as disciplinas escolares acabem sendo uma espécie de reflexo das carreiras universitárias", o que pode estar diretamente relacionado a dificuldades de compreender a concepção de interdisciplinaridade.

A recomendação de políticas públicas curriculares para a realização de práticas interdisciplinares é justificada pela fragmentação do saber como um problema para na formação dos sujeitos que frequentam à escola. Tal fragmentação pode ser explicada pela instituição de um modelo educacional decorrente do ideal da ciência positivista, com grande influência para o pensamento científico moderno (séc. XIX), mas que hoje já se mostra ineficaz para o tipo de aluno que se deseja formar. De acordo com Mosé (2013, p.51):

\footnotetext{
A falta de conexão da escola, tanto com a sociedade quanto consigo mesma, não é apenas prejudicial para o desenvolvimento cognitivo dos alunos, que se dá pela capacidade de fazer relações cada vez mais amplas e complexas, mas prejudica também as relações humanas, a prática da justiça social, o exercício da cidadania [...].
}

Assim, vemos que as discussões acerca da formação de professores em cursos de licenciatura, e também na escola, não se esgotam, sendo recorrentes os discursos em prol da necessidade de incentivar a formação de professores para atender as necessidades e demandas da educação básica. Mas como os licenciandos percebem a sua formação quando no exercício da docência, ainda, em processo de formação acadêmica?

Estágio supervisionado compondo um cenário de expectativas, experiências e perspectivas para futuros professores

Desde as reformas implementadas nos cursos de licenciatura pelas Resoluções $n^{\circ} 1$ e $n^{\circ} 2$ (BRASIL, 2002), os acadêmicos são incentivados, desde o início da graduação, a pensar o exercício da docência em diferentes disciplinas didático-pedagógicas, bem como em projetos de ensino, pesquisa e extensão desenvolvidos em parceria com a escola, contudo, é no momento dos estágios supervisionados, quando assumem o papel de professor/a que surgem suas maiores preocupações e dificuldades.

O aumento de carga horária dos estágios supervisionados, que passou a ser de 400h, como já dito, embora garanta ganhos em função de um maior tempo para o exercício da prática no ambiente escolar, implica 
também em algumas dificuldades, especialmente em cidades com poucas escolas de Ensino Médio ou em grandes centros onde há muitas instituições com cursos de licenciatura. Receber e acompanhar estagiários de diferentes áreas, por um maior período de tempo, tem feito com que as escolas criem estratégias que, por vezes, inibe ou impossibilita a realização de estágios, contrariando o recomendado pela legislação e pela literatura, pois,

DOI https://doi.org/10.31639/rbpfp.v\%vi\%i.192

de acordo com a concepção dialética, teoria e prática são consideradas, na proposta curricular, o núcleo articulador da formação do profissional, na medida em que os dois elementos são trabalhados de forma integrada, constituindo uma unidade indissociável. (FÁVERO, 2011, p.69)

No curso pesquisado, os estágios supervisionados estão organizados em estágios de observação da docência (Estágio I), de docência compartilhada com o professor da escola (Estágio II) e de regência de classe com o acompanhamento de professor titular da turma da (Estágio III), sendo todos estes orientados e supervisionados por professores do curso de licenciatura em Química, em parceria com os docentes das instituições parceiras da universidade. Sobre essa organização dos estágios, os licenciandos manifestam-se (quadro 1), especialmente quanto ao tempo estipulado para os estágios.

\section{QUADRO 1: PERCEPÇÃO DOS ESTAGIÁRIOS SOBRE O TEMPO DESTINADO AOS ESTÁGIOS}

\begin{tabular}{|c|c|}
\hline \multirow{3}{*}{$\begin{array}{l}\text { Sobre o tempo para } \\
\text { o estágio }\end{array}$} & Eu achei um tempo suficiente de observação no estágio I(...) $\left(\mathrm{L}_{4}\right)$ \\
\hline & $\begin{array}{l}\text { Quanto antes à gente atuar é melhor porque vemos as dificuldades } \\
\text { de quem precisa realmente aprender }(\ldots)\left(L_{5}\right)\end{array}$ \\
\hline & $\begin{array}{c}\text { Não tive docência compartilhada no estágio II, mas o problema foi } \\
\text { com a professora }(. . .) \text { teria que ter mais um para docência, só o III } \\
\text { é pouco tempo. }\left(L_{8}\right)\end{array}$ \\
\hline
\end{tabular}

Fonte: autores

Os licenciandos relataram que gostariam de dispor mais tempo para exercer as atividades como responsáveis pela turma, já que consideram está uma fase importante para a construção da aprendizagem e tomada de decisões em sala de aula. A questão do tempo de docência está no âmbito das dificuldades com relação à forma como a escola e a universidade vêm se organizando para atender a formação de professores.

Diante de suas prováveis dificuldades, as escolas localizadas na região onde este estudo foi realizado, passaram a desenvolver suas próprias regras organizacionais para atender a realização dos estágios em seu espaço. Uma dessas "regras" é não disponibilizar turmas para estágio de docência no $3^{\circ}$ trimestre, outra é não disponibilizar turmas de $3^{\circ}$ ano do Ensino Médio, além do fato de haver professores que não aceitam ter estagiários. Diante disso, a universidade faz ajustes, procurando manter o maior número de disciplinas de estágio no primeiro semestre, ao mesmo tempo que precisa organizar a matriz curricular de modo a atender as finalidades formativas dos alunos, o que mostra o quão complexo é a formação inicial de professores e a importância das "agências formadoras de professores perceberem essa complexidade da formação" (LEITE, GHEDIN, ALMEIDA, 2008, p. 24).

Com relação à recepção e acolhida na escola, ao analisar as percepções dos licenciandos, procuramos identificar como a escola recebe os estagiários e se isso teria influenciado para a permanência do estagiário na 
escola nos estágios subsequentes. Considerando que o Estágio I seja o primeiro contato do estagiário com a escola, com professores e alunos, é de suma importância o aluno ser bem recebido pela equipe diretiva e pelo/a professor/a titular. Essa experiência pode ser tanto positiva como negativa e, certamente, vai definir a decisão do licenciando em permanecer, ou não, na mesma escola nos Estágios II e III.

Para parte dos estagiários a acolhida na escola foi boa, sendo motivador para a realização do estágio, construindo desde o início uma relação com professores e alunos que foi determinante para o modo como viram a escola e como pensaram o seu trabalho com os alunos, como indicado nas manifestações que seguem:

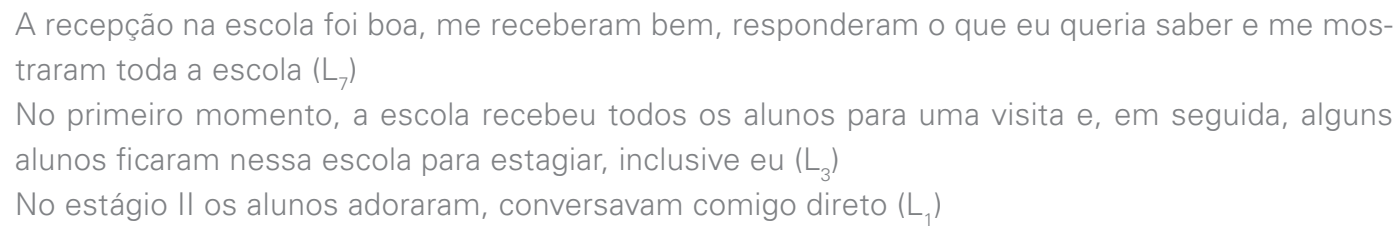

No entanto, para outros estagiários, a entrada na escola e na sala de aula foi difícil, relataram sentir que pareciam ser um incômodo, como indicado a seguir:

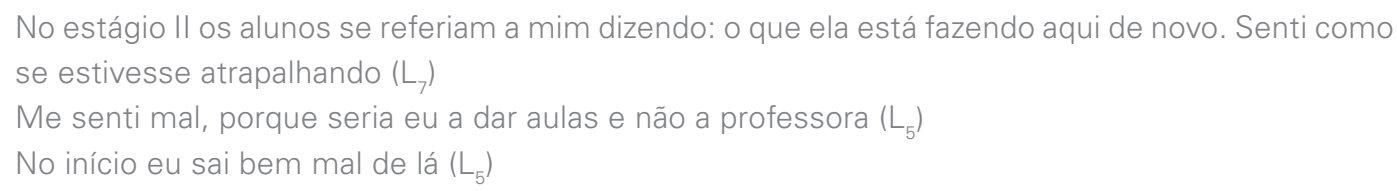

Acredita-se, que parte desse desconforto seja porque algumas escolas não se veem como instância formadora de professores e apenas abrem a escola para o estágio, logo, não orientam os estagiários nesse momento inicial de entrada na profissão docente. Com o passar do tempo os licenciandos dizem que vão se acostumando e que os alunos da escola passam a ter uma relação mais "respeitosa", mas destacam que essa primeira experiência poderia ser melhor se tivessem uma mediação mais efetiva da escola, porque com o tempo passam a contar com o seu trabalho individual para "conquistar" os alunos.

Eu acho que a professora não preparou eles para me receber $\left(\mathrm{L}_{5}\right)$

Quando cheguei lá ela nem falou nada para eles, não fui apresentada $\left(L_{7}\right)$.

(...) quando comecei a dar aulas que a professora não dava (laboratório), eles começaram a gostar de $\operatorname{mim} \ldots\left(L_{5}\right)$

A dificuldade desse primeiro contato pode se dar em função de não haver na escola uma política para o atendimento/acolhimento aos estagiários, pois, normalmente, essa acolhida depende do/a coordenador/a pedagógica, que, por sua vez, desempenha muitas outras funções na escola. O excesso de trabalho dos professores e coordenadores pedagógicos nas escolas também precisa ser considerado para o que os alunos relatam como sendo uma experiência boa ou ruim.

No turno da manhã a coordenadora era muito atarefada e não conseguia atender os estagiários com a atenção necessária. No turno da noite, as coordenadoras (talvez não sejam tão atarefadas) são mais atenciosas (L9)

A recepção não foi muito boa. Inicialmente me receberam até bem, mas logo depois tive problemas com a coordenação, não conseguia falar com ela. Os professores eram muito bons e me receberam muito bem, porém a coordenação não (L8) 
Diante dessas considerações é possível inferir que, ao entrar na escola para a realização dos estágios, os licenciandos sintam-se inseguros e fiquem em dúvida sobre como se comportar e como "colocar em prática" seus conhecimentos sobre ensino e educação escolar, por isso, a importância de terem uma boa experiência nesse primeiro contato com o seu futuro ambiente de trabalho.

Para Leite, Ghedin e Almeida (2008), é fundamental o aluno conseguir fazer a articulação teoria/prática, de modo a compreender que o vínculo entre universidade e escola é necessário para o desenvolvimento da formação profissional durante os estágios supervisionados. Esses autores relacionam as dificuldades enfrentadas pelos "novatos" com a formação que tiveram na universidade, muitas vezes distante do modo de funcionamento das escolas, sendo o período dos estágios um momento em que seria possível evidenciar esses distanciamentos, ao mesmo tempo em que se pode trabalhar para aproximar essas duas vivências.

Ao longo dos estágios, os licenciandos são orientados por professores na universidade, devendo ter também supervisão (acompanhamento) dos professores titulares na escola, sendo essa etapa formativa da docência realizada, conjuntamente, pela universidade e pela escola. Com relação ao acompanhamento dos professores titulares, mais da metade dos estagiários pesquisados, manifestaram descontentamento por não haver trabalho conjunto com os professores titulares na organização e planejamento de ensino, especialmente no estágio de docência compartilhada, quando os professores, muitas vezes, não aproveitavam/valorizavam as colaborações dos estagiários para a realização de atividades pedagógicas, como apontado nas seguintes manifestações:

A professora pedia para eu copiar no quadro o que estava no caderno dela. Não havia encontros para planejamento. (L4)

Eu só acompanhava o professor. Não havia encontros e o professor não fazia planos de aula. (L7)

É importante esse acompanhamento, especialmente no estágio de docência compartilhada, no qual o aluno deveria aprender com o professor titular a organizar os planejamentos de ensino, considerando ser a etapa de planejamento um momento importante de reflexão de modo a "superar a cultura escolar que ainda carrega vícios de uma perspectiva tecnicista e conservadora da educação" (LEITE, GHEDIN, ALMEIDA, 2008, p.34). De acordo com os autores, o que talvez dificulte uma análise crítica da prática docente em sala de aula durante os estágios supervisionados seja haver pouco envolvimento e parceria entre universidade e escola para pensar a formação de professores.

A visão dos formadores, tanto da escola quanto da universidade, é fundamental, especialmente no processo de planejamento das ações pedagógicas, pois este é um exercício de autonomia que contribui para que o futuro professor reflita sobre as questões teóricas envolvidas nas práticas desenvolvidas e "ao fazer a reflexão entre teoria e prática, o aluno/professor transforma o saber e reconstrói sua identidade profissional, refletindo em melhoria na qualidade de ensino" (PELOZO, 2007, p.2). Por isso, é importante que o licenciando tenha, também na escola, espaços de discussão e reflexão sobre seus planejamentos acompanhado de um professor que exerça a profissão docente há mais tempo.

Embora os encontros com os professores da escola devam acontecer com mais frequência durante o estágio de docência compartilhada, também no estágio onde os licenciandos assumem a regência de classe (Estágio III) é importante à presença do professor da escola para auxiliar o estagiário nas decisões sobre as ações pedagógicas planejadas por ele. Porém, para a maioria dos estagiários, o planejamento das atividades não era realizado em conjunto com o professor titular, sendo que, em alguns casos não havia encontros ou discussões em nenhum momento durante o período de estágio de regência. 


\begin{abstract}
Havia encontros semanais com a professora, mas a professora não se envolvia no planejamento, eu tinha liberdade de fazer o que eu queria. (L9)

O planejamento era feito apenas com o professor orientador da universidade. (L6)

A professora não acompanhava o que eu fazia com os alunos e muito menos olhava meus planejamentos. Simplesmente me largou na turma. (L7)
\end{abstract}

Vê-se nesses relatos que os estagiários apontam a necessidade de haver participação dos professores da escola durante a realização do estágio. A licencianda L5 destaca a importância da parceria da professora titular durante o seu estágio.

A relação entre estagiária e professora era boa. Ela se importava e se preocupava em saber como estavam indo as aulas e como a turma estava se comportando. Os encontros eram semanais, além de contatos por e-mail e telefone.

Segundo o parecer do CNE/CP 09/2001 (BRASIL, 2001, p.18), deve-se lembrar que o estágio, necessário à formação dos futuros professores, fica prejudicado pela ausência de espaço institucional que assegure um tempo de planejamento conjunto entre os profissionais dos cursos de formação e os da escola de educação básica. Sem dúvida, a falta de acompanhamento e supervisão dos professores titulares, torna-se um problema que gera insegurança e torna a vivência do estágio uma má experiência. Por outro lado, o acompanhamento, por parte de supervisores e professores na escola, é considerado importante e se torna motivador para o exercício da profissão docente. As falas que seguem mostram essas diferentes experiências.

Isso depende do professor, eu fiz tudo com a minha professora (elaborei e corrigi provas, dei aula com ela me observando) (...) a parceria com o professor ajuda, pois ela ia dando dicas (L2)

Tinha reunião para planejamento sempre nos dois períodos antes da aula de estágio, e tínhamos um contato mais assíduo por email e rede social (L9).

A gente só se reunia [eu e a professora] na hora do recreio (L2)

Senti falta da parceria do professor para fechar as notas, devido ao novo método de avaliação (L9) No meu estágio III eu não tive parceria da professora titular, isso foi ruim (L9)

Não tive apoio nenhum do professor, fiz tudo sozinha na escola. (L7)

Acreditamos ser preciso repensar os papéis da escola e da universidade, ambos como agências formadoras de professores, considerando que estes se constituem como um momento importante e decisivo para a definição da escolha da docência como exercício profissional. Pois, é nesse período que o estagiário, conhecendo suas atribuições em seu futuro local de trabalho, poderá, ainda, decidir sobre seguir, ou não, na carreira docente.

Uma outra questão relatada pelos estagiários como sendo um problema se refere à falta de formação na universidade e na escola para contemplar o atendimento a alunos que necessitam de inclusão, pois não se sentem preparados para planejar ações pedagógicas inclusivas. Afirmam que:

Há falta de estrutura da universidade para preparar e da escola para receber futuros professores para o trabalho com alunos com deficiência (L10)

Tem essa menina cega, um menino cadeirante, dois autistas, dois com paralisia cerebral, e um com síndrome de Tourette, e nenhum professor sabe trabalhar com eles (...) não se está fazendo inclusão e sim integração (L10) 
Gaiger, Pinto e Pitano (2010), afirmam que os estagiários se deparam com algumas cenas e situações vivenciadas nas escolas durante os estágios que irão remeter a um primeiro e, por vezes, decisivo olhar sobre a profissão na qual estão se preparando para exercer e esse olhar produz efeitos sobre as perspectivas desses estagiários acerca da profissão docente. Com relação à inclusão, algumas situações poderiam ser positivas no processo de formação dos estagiários, caso estes se sentissem mais seguros em trabalhar com alunos incluídos, "pois ajudaria para o professor pensar em outras metodologias para ensinar." (L10)

Vê-se, assim, que diferentes fatores podem contribuir para atender as expectativas dos licenciandos quando realizam seus estágios supervisionados. Algumas dessas se referem à estrutura das escolas, outras têm relação com a organização da prática de estágio pela universidade (seleção de escolas e professores titulares). De qualquer modo, é necessário estarmos atentos para estabelecer e melhorar as parcerias entre as escolas de Educação Básica e a universidade, considerando que essa articulação é essencial para o acompanhamento e supervisão do trabalho docente durante o período de estágio. Para Pelozo (2007),

A prática de ensino e o estágio não garantem uma preparação completa para o magistério, mas possibilita que o futuro educador tenha noções básicas do que é ser professor nos dias atuais, como é a realidade dos alunos que frequentam a escola, entre outras. Essa oportunidade de observação e reflexão sobre a prática permitirá que o aluno/estagiário reafirme sua escolha pela profissão... (p. 2)

Sobre as motivações e expectativas durante o período de estágio, alguns licenciandos apontam que a experiência foi motivadora, "pois, quando entrei na sala de aula, notei que não é apenas ensinar, vai muito além, pois trabalhamos com pessoas" (L6). Para os estagiários, a sala de aula, é um lugar de identidade cultural, reconhecendo que diferentes credos, raça, opção sexual estão presentes neste contexto de formação.

Alguns apontaram que a falta de estrutura da escola e de parceria com os professores são fatores que tornam a experiência ruim, como apontado a seguir.

Os estágios I e II foram muito bons. O Estágio III nem tanto, porque não pude fazer como e onde eu queria (...) Eu queria fazer o estágio com uma professora e tive que fazer com outra. Isso me desmotivou muito. $\left(\mathrm{L}_{\mathrm{g}}\right)$

Dependendo da escola é desmotivador, pela (falta) de estrutura disponível e a dificuldade de acesso aos recursos $\left(\mathrm{L}_{4}\right)$

O meu estágio foi desmotivador (...), ia até lá e não tinha aula por troca de horários e eles não me avisavam... $\left(\mathrm{L}_{8}\right)$

Em relação às perspectivas para o exercício da profissão, os estagiários se manifestaram sobre o exercício da docência na Educação Básica, a partir das experiências vivenciadas nos estágios. As respostas foram distintas, apontando para perspectivas diferentes com relação ao plano profissional dos licenciandos. Alguns indicaram ter perspectivas de seguir a carreira docente, frente à possibilidade de desenvolvimento de metodologias inovadoras de ensino, como destacado por L7,

Espero continuar com a metodologia diferenciada, pois é como os alunos participam e gostam das aulas, mas para isso a escola também deve estar de acordo e os outros professores também precisam adaptar coisas diferentes em suas aulas, o que eu acho difícil acontecer. $\left(L_{7}\right)$

Assim, mostram a expectativa de experienciar, nos estágios, o desenvolvimento de metodologias ativas que discutem na universidade. Ao mesmo tempo, expressam que muitas ideias não podem ser concretizadas 
porque durante o estágio, quando pretendem assumir um ensino mais ativo, se veem executando as aulas baseadas num modelo tradicional, carregando consigo uma perspectiva conservadora da educação (LEITE, GHEDIN, ALMEIDA, 2008, p. 23-36), e afirmam que para vencer esse desafio é fundamental contarem com a parceria do/ professor/a titular.

Os sujeitos da pesquisa reconhecem que se o/a docente tem uma formação disciplinar, talvez a parceria não seja profícua, sendo necessário pensar na proposição de projetos de educação que enfrente a "fragilidade" da prática docente que não articula o diálogo entre conteúdos e componentes curriculares de diferentes áreas, em dimensão interdisciplinar, como recomendado pela reforma do Ensino Médio Politécnico (SEDUC/ RS, 2011). Mas a principal dificuldade referida pelos estagiários, foi em relação à desvalorização da profissão docente, uma vez que o pouco prestígio dado à carreira cria poucas perspectivas de sucesso na profissão pelos licenciandos em formação.

Tem muita coisa a fazer, porém o centro de tudo, acredito, seja a valorização dos profissionais e da educação. $\left(L_{4}\right)$

Minha perspectiva é muito boa, me sinto à vontade trabalhando com adolescentes, porém tenho a intenção de ministrar aulas para o ensino superior. $\left(L_{2}\right)$

Ao serem questionados sobre como são preparados na universidade para os estágios, os licenciandos afirmam que a universidade tem uma ideia "distorcida" sobre como a escola funciona, de como lidar com os problemas para ensinar alunos que não tem interesse pela escola e, também, atender o dia a dia da sala de aula com o ensino no seu campo de conhecimentos. Ao entrar na escola para a realização dos estágios, o futuro professor tem no contato direto com os alunos uma percepção sobre o que é ser professor.

Sendo assim, as considerações feitas pelos licenciandos sobre os estágios nos levam a pensar outras formas de rever e envolver a escola nessa etapa da formação docente. Não apenas compreendendo-a como um espaço para a realização da prática profissional, mas também como lugar de construções teóricas e de pesquisa, tornando-se um desafio vislumbrarem a escola como seu ambiente de trabalho, mobilizando conhecimentos, reflexões e práticas associadas aos saberes docentes, entre os quais está o aprendizado que tiveram na universidade (TARDIF, 2007). Em função disso, a tríade - licenciando, orientador na universidade e supervisor na escola - deve estar em sintonia, fazendo com que o estágio seja um espaço produtivo e enriquecedor para o futuro docente. 
DOI https://doi.org/10.31639/rbpfp.v\%vi\%i.192

\section{CONSIDERAÇÕES FINAIS}

Tendo em vista a relevância dos estágios supervisionados para a formação dos professores, é importante ouvir as percepções de licenciandos acerca dos mesmos, pois estes relatam diferentes situações e sentimentos a partir das experiências e aprendizagens vividas no período dos estágios (ALVES, 2011).

A partir da pesquisa realizada com estagiários de um curso de licenciatura em Química foi possível reconhecer que universidade e escola devem intensificar o diálogo, de modo a possibilitar vivências positivas para os professores em formação nos primeiros contatos com a profissão docente, diminuindo um possível distanciamento entre o estágio ideal e o estágio real vivenciado pelos licenciandos (PIMENTA, 2012).

Se por um lado, o período de estágio é um espaço para a realização de ações didático-pedagógicas inovadoras, ao se depararem com a escola e com a heterogeneidade e demandas nas turmas, os estagiários se sentem inseguros e, muitas vezes, (re)produzem um ensino mais tradicional. Considera-se que essa problemática, se dá também pela falta de parceria com o professor da escola, sendo esse um dos fatores que acentua e contribui para as dificuldades enfrentadas pelos licenciandos durante os estágios.

Percebe-se que os licenciandos enfrentam alguns desafios quando buscam, no período dos estágios, vivenciar e propor práticas de ensino inovadoras, como o distanciamento entre universidade e escola e a falta de acompanhamento do professor titular da escola/turma. Nesse sentido, é preciso pensar modos de fazer com que o professor da Educação Básica se reconheça como um formador, para assim a escola não ser mais considerada apenas um espaço de prática, mas sim de formação humana e profissional.

Finalizando, consideramos a pesquisa importante, pois mostra que, embora, a universidade atenda a legislação e que políticas públicas proponham o desenvolvimento de ações de formação no ambiente escolar desde o início dos cursos de licenciatura, a realização dos estágios é considerada pelos licenciandos como o momento no qual se veem como professores em exercício, podendo ser esta experiência definidora para as perspectivas com relação ao exercício da docência. 
DOI https://doi.org/10.31639/rbpfp.v\%vi\%i.192

\section{REFERÊNCIAS}

ALVES, Nilda. Formação de Professores: pensar e fazer. 11 ed. São Paulo: Cortez, 2011, 112p.

AUGUSTO, Thaís Gimenez da Silva et al. Interdisciplinaridade: concepções de professores da área ciências da natureza em formação em serviço. Ciência \& Educação, São Paulo, v. 2, n. 10, p.277-289, ago. 2004. Disponível em: http://www.scielo.br/scielo.php?pid=S1516-73132004000200009\&script=sci_abstract\&tlng=pt> Acesso em: 04 Jan.2018.

BARDIN, Laurence. Análise de Conteúdo. São Paulo: Edições 70, 2011. 279 p. Traduções de Luís Antero Reto e Augusto Pinheiro

BRASIL, CNE/CEB. Resolução CNE/CEB n 5/2011, de 30 de Janeiro 2012. Brasília/DF, 2012. Disponível em: < http://portal.mec.gov.br/index.php?option=com_docman\&view=download\&alias=9864-rceb002-12\&ltemid=30192> . Acesso em: 27 de Out. 2015

CNE/CP. Parecer CNE/CP 09/2001, de 08 de Maio de 2001. Brasília/DF, 2001.Disponível em:< http:// portal.mec.gov.br/cne/arquivos/pdf/009.pdf>. Acesso em: 25 Set. 2014.

CNE/CP. Parecer CNE/CP 09/2007, de 05 de Dezembro de 2007. Brasília/DF, 2007.Disponível em: < http://portal.mec.gov.br/cne/arquivos/pdf/2007/pcp009_07.pdf>. Acesso em: 25 de set. 2014.

CNE/CP. Parecer CNE/CP 28/2001, de 02 de Outubro de 2001. Brasília/DF, 2001. Disponível em: < http://portal.mec.gov.br/cne/arquivos/pdf/028.pdf >. Acesso em: 25 de set. 2014.

, CNE/CP. Resolução CNE/CP 01/2002, de 18 de Fevereiro de 2002, Resolução CNE/CP 02/2002, de 19 de Fevereiro de 2002. Brasília/DF, 2002. Disponível em:< http://portal.mec.gov.br/cne/arquivos/pdf/rcp01_02. pdf http://portal.mec.gov.br/seesp/arquivos/pdf/res2_2.pdf>. Acesso em: 25 de set. 2014.

CNE/CP. Resolução CNE/CP 01/2015, de 1 de Julho de 2015. Brasília/DF, 2015.Disponível em:http:// portal.mec.gov.br/index.php?option=com_docman\&view=download\&alias=70431-res-cne-cp-002-03072015pdf\&category_slug=agosto-2017-pdf\&Itemid=30192. Acesso em:04 Jan. 2018.

, Lei de Diretrizes e Bases da Educação Nacional. Lei nº 9.394, de 20 de dezembro de 1996. Disponível em:<http://portal.mec.gov.br/seesp/arquivos/pdf/lei9394_ldbn1.pdf> Acesso em: 04. Jan. 2018.

BOVO, Marcos Clair. Interdisciplinaridade eTransversalidade como Dimensões da Ação Pedagógica. Urutágua: Acadêmica Multidisciplinar, Paraná, v. 07, p.1-11, 03 dez. 2004. Disponível em: <http://www.urutagua.uem. br/007/07bovo.htm>. Acesso em: 13 out. 2015.

FRANCO, Maria Laura Plubisi Barbosa. Análise de Conteúdo. 3.ed. Brasília: Liber Livro, 2008. 80 p.

FÁVERO, Maria de Lourdes de A. Universidade e estágio curricular: subsídios para discussão. In ALVES, Nilda (org.) Formação de Professores: pensar e fazer. 11ed. São Paulo: Cortez, 2011.

GAIGER, Paulo J. G.; PINTO, Maria das G. G.; PITANO, Sandro de C. Currículo e Projeto Pedagógico, Estágio e Formação Continuada: outros olhares e outras reflexões. Pelotas: Ed. da UFPEL, 2010. 
GARCIA, Irene T.S.; KRUGER, Verno. Implantação Das Diretrizes Curriculares Nacionais Para Formação De Professores de Química em Uma Instituição Federal De Ensino Superior: Desafios e Perspectivas. Química Nova, Brasil. v.32, n.8, p.2218-2224, abril/out 2009. Disponível em:<http://quimicanova.sbq.org.br/imagebank/ pdf/Nol32No8_2218_38-ED08558.pdf> Acesso em: 04 Jan.2018.

LEITE, Yoshie U.; GHEDIN, Evandro; ALMEIDA, Maria I.. Formação de Professores: caminhos e descaminhos da prática. Brasília: Líber Livro editora, 2008.

LÜDKE, Menga; ANDRÉ, Marli E. D. A. de. Pesquisa em Educação: abordagens qualitativas. 1. Ed. São Paulo: E.P.U, 1986. 99 p.

MANZINI, E. J. Entrevista semi-estruturada: análise de objetivos e de roteiros In. Seminário Internacional Sobre Pesquisa E Estudos Qualitativos, 2. 2004, São Paulo. A pesquisa qualitativa em debates. Bauru: Usc, 2004. 10 p. Disponível em: <https://www.marilia.unesp.br/Home/Instituicao/Docentes/EduardoManzini/ Manzini_2004_entrevista_semi-estruturada.pdf>. Acesso em: 19 Out. 2015.

MALACARNE, Vilmar. Os professores de Química, Física e Biologia da região oeste do Paraná: Formação e atuação.2007. 261 f. Tese (Doutorado) - Curso de Filosofia Licenciatura Plena, Faculdade de Educação da Universidade de São Paulo, Universidade de São Paulo, São Paulo, 2007. Disponível em: <http://www.educadores.diaadia.pr.gov.br/arquivos/File/2010/artigos_teses/quimica/form_atuac_prof_quim_fis_bio_oeste_pr_tese. pdf>. Acesso em: 19 Out. 2015.

MELO, Geovana Ferreira. Torna-se professor: a formação desenvolvida nos cursos de Física, Matemática e Química da Universidade Federal de Uberlândia. 2007. 230 f. Tese (Doutorado) - Curso de Pedagogia, Programa de Pós-graduação em Educação, da Universidade Federal de Goiás, Universidade Federal de Goiás, Goiânia, 2007. Disponível em: <https://portais.ufg.br/up/6/o/Tese Geovana Ferreira.pdf>. Acesso em: 19 Out. 2015.

MOSÉ, Viviane. A escola e os desafios contemporâneos organização e apresentação: 1 ed. Rio de Janeiro: Civilização Brasileira, 2013.336p.

NÖRNBERG, Marta. (Org.). Formação em contextos de estágio e desenvolvimento profissional. 1ed.São Leopoldo: Oikos Editora, 2017, v. 1, p. 133-155. Disponível em:< https://wp.ufpel.edu.br/obeducpacto/files/2017/10/Formacao-em-contextos-de-estagio-e-book.pdf> Acesso em: 04 Jan. 2018.

PELOZO, Ritta de C. B. Prática de Ensino e o Estágio Supervisionado enquanto Mediação entre Ensino, Pesquisa e Extensão. Revista Científica Eletrônica de Pedagogia, Brasil. Ano V, n. 10, 2007. Disponível em: <http://www.revista.inf.br>: Acesso em: 15 de Maio 2014.

PIMENTA, Selma Garrido. O Estágio na Formação de Professores: Unidade Teoria e Prática? 11.ed. São Paulo: Cortez, 2012, 224p.

PEREIRA, Júlio Emílio Diniz. As licenciaturas e as novas políticas educacionais para a formação docente. Educação \& Sociedade: Educ. Soc, Campinas, v. 68, n. 17, p.109-125, dez. 1999. Disponível em: <http:// www.scielo.br/pdf/es/v20n68/a06v2068.pdf>. Acesso em: 19 out. 2015

ROSA, Maria Inês Petrucci. Formação docente, Identidade profissional e a disciplina escolar: práticas curriculares no ensino médio. Zetetiké, Unicamp, v, 18, número temático 2010. Disponível em:< https://periodicos. sbu.unicamp.br/ojs/index.php/zetetike/article/viewFile/8646659/13561> Acesso: 04 Jan.2018. 
SILVA, M. Complexidade da formação de professores: saberes teóricos e saberes práticos.. São Paulo: Editora UNESP; São Paulo: Cultura Acadêmica, 2009. 114 p. Disponível em:< http://www.creasp.org.br/biblioteca/wp-content/uploads/2012/05/Complexidade_da_formacao_de_professores-NOVA-P4.pdf> Acesso: 04 Jan.2018.

SEDUC/RS. Secretaria Estadual de Educação do rio Grande do Sul. Proposta Pedagógica para o Ensino Médio Politécnico e Educação Profissional Integrada ao Ensino Médio (2011-2014). Porto Alegre, 2011. Disponível em: http://servicos.educacao.rs.gov.br/dados/ens_med_proposta.pdf> Acesso em: 04 Jan. 2018.

TARDIF, Maurice. Saberes docentes \& formação profissional. 8. ed. Rio de Janeiro: Vozes, 2007328 p.

VEIGA-NETO, Alfredo José da. Currículo, Disciplina e Interdisciplinaridade. Ciência do Esporte.São Paulo, v. 17, n. 2, p.105-119, 1996. Disponível em: <http://cev.org.br/biblioteca/revista-brasileira-ciencias-esporte-1996-n2-v17/>. Acesso em: 13 Out. 2015. 